\title{
Incidence of hepatocellular carcinoma after HCV eradication: assessing the risk
}

\author{
Marcello Maida $^{1}$, Fabio Salvatore Macaluso $^{2}$ \\ ${ }^{1}$ Gastroenterology and Endoscopy Unit, S. Elia-Raimondi Hospital, Caltanissetta, Italy; ${ }^{2}$ Department of Internal Medicine, Villa Sofia-Cervello \\ Hospital, Palermo, Italy \\ Correspondence to: Marcello Maida, MD. Gastroenterology and Endoscopy Unit, S. Elia-Raimondi Hospital, Caltanissetta, Italy. \\ Email: marcello.maida@hotmail.it. \\ Provenance and Peer Review: This article was commissioned by the Editorial Office, Hepatobiliary Surgery and Nutrition. The article did not undergo \\ external peer review. \\ Comment on: Ioannou GN, Beste LA, Green PK, et al. Increased risk for hepatocellular carcinoma persists up to 10 years after HCV eradication in \\ patients with baseline cirrhosis or high FIB-4 scores. Gastroenterology 2019;157:1264-1278.e4.
}

Submitted Oct 04, 2019. Accepted for publication Oct 16, 2019.

doi: $10.21037 /$ hbsn.2019.10.17

View this article at: http://dx.doi.org/10.21037/hbsn.2019.10.17

Hepatocellular carcinoma (HCC) is the third leading cause of cancer-related death and the first cause of death in patients with cirrhosis. An increasing incidence worldwide and poor prognosis are reported despite the application of screening protocols and potentially radical therapies (1).

The oncogenesis of HCC is strictly related to the presence of chronic inflammation, and most commonly arises on the background of a cirrhotic liver, mainly secondary to HBV or HCV infections and alcoholic steatohepatitis (ASH) or non-alcoholic steatohepatitis (NASH). As a consequence, the etiological treatment of the underlying chronic liver diseases plays a fundamental role in the primary prevention of HCC. In this line, the recent introduction of effective therapies for HCV based on the use of direct-acting antivirals (DAAs), with a rate of sustained virological response (SVR) approaching 100\%, has made it possible to take a step forward in reducing the incidence of HCC.

The benefit of viral eradication with IFN-based therapies on HCC incidence had been previously demonstrated by two meta-analyses $(2,3)$. Similarly, DAAs induced SVR has been confirmed to reduce the risk of HCC occurrence $(4,5)$. Nonetheless, the risk of HCC after antiviral therapy is not canceled, and it varies widely between patients. Therefore, stratifying the risk in the individual patient is essential, but it still remains a difficult task. In this regard, a model estimating the risk of HCC after antiviral treatment has been recently developed (6). The study shows that the risk of HCC mainly depends on the presence of pre-treatment cirrhosis and the achieving of SVR after therapy. As a consequence, the risk is higher in the group of patients with cirrhosis and without SVR (5.0 per 100 patient-years), lower in patients with cirrhosis but achieving an SVR (2.2 per 100 patient-years), even lower in patients without cirrhosis and without SVR (1.1 per 100 patient-years), and minimum in patients without cirrhosis and SVR $(0.3$ per 100 patientyears). Among the 23 potential predictors evaluated, four (age, platelet count, serum AST/ALT ratio and albumin) accounted for most of the prediction. This data further confirms the benefit of antiviral therapy in reducing the risk of HCC and confirm liver cirrhosis as an independent risk factor that persists even after viral eradication.

Nevertheless, data from the literature available so far only provide a static picture of the overall HCC risk after antiviral therapy, but how this risk varies over time is extremely complex, and it is still unknown. After SVR, patients become older, they may undergo a variable reduction in the degree of basal fibrosis or acquire additional risk factors for the progression of liver disease (e.g., obesity, alcohol consumption, diabetes, and so on).

A recent study by Ioannou and colleagues has been conducted with the aim to assess the changes in HCC annual incidence over time following HCV eradication and identify dynamic markers of HCC risk (7). In this study, authors retrospectively reviewed a cohort of 48,135 patients from the Veterans Health Administration database: 29,033 of them were treated with DAA-only regimens, and 19,102 with "IFNbased" regimens. Among these, 9784 had a pre-treatment 
cirrhosis and 1509 finally developed HCC after a minimum of 180 days since initiation of the antiviral treatment.

Patients with pre-treatment cirrhosis achieving SVR had a different risk over time depending on the treatment regimen. In patients performing DAAs a progressive reduction of $\mathrm{HCC}$ risk over the first 4 years was observed both in patients with FIB-4 $\geq 3.25$ (from $3.8 \%$ to $2.4 \%$ ) and in those with FIB-4 $<3.25$ (from $1.4 \%$ to $0.5 \%$ ). Unfortunately, due to the recent introduction of DAAs, a follow-up over 4 years was not available.

On the contrary, patients with pre-treatment cirrhosis with SVR after IFN-based regimens have had no reduction in HCC risk that was consistently above $2 \%$ even after 10 years after therapy in patients with FIB- $4 \geq 3.25$, while in patients with FIB- $4<3.25$ the risk remained $<1 \%$.

Moreover, the drop of FIB-4 score, from pre-treatment values $\geq 3.25$ to post-treatment $<3.25$ after SVR, is associated with reduced HCC risk both in patients treated with DAAs or IFN-based regimens.

Despite some limitations, in particular the almost exclusively male population and the retrospective design, data from this study are helpful to better stratify the risk of HCC after HCV eradication over time. This could be useful, for instance, to better define the at-risk population that must continue surveillance. In this regard, patients with pre-treatment cirrhosis, especially without SVR, and patients without cirrhosis but with a FIB-4 score $>3.25$, especially with a FIB-4 score persistently $>3.25$ even after SVR, have a significant risk and surveillance must continue to be offered. In the future, studies with a longer follow-up will be needed to understand the dynamic risk of HCC after DAAs better.

\section{Acknowledgments}

Funding: None.

\section{Footnote}

Conflicts of Interest: All authors have completed the ICMJE uniform disclosure form (available at https://hbsn.amegroups. com/article/view/10.21037/hbsn.2019.10.17/coif). The authors have no conflicts of interest to declare.

Ethical Statement: The authors are accountable for all aspects of the work in ensuring that questions related to the accuracy or integrity of any part of the work are appropriately investigated and resolved.
Open Access Statement: This is an Open Access article distributed in accordance with the Creative Commons Attribution-NonCommercial-NoDerivs 4.0 International License (CC BY-NC-ND 4.0), which permits the noncommercial replication and distribution of the article with the strict proviso that no changes or edits are made and the original work is properly cited (including links to both the formal publication through the relevant DOI and the license). See: https://creativecommons.org/licenses/by-nc$\mathrm{nd} / 4.0 \%$.

\section{References}

1. Maida M, Malizia G, Affronti A, et al. Screening and surveillance for hepatocellular carcinoma: perspective of a new era? Expert Rev Anticancer Ther 2016;16:1291-302.

2. Singal AK, Singh A, Jaganmohan S, et al. Antiviral therapy reduces risk of hepatocellular carcinoma in patients with hepatitis C virus-related cirrhosis. Clin Gastroenterol Hepatol 2010;8:192-9.

3. Morgan RL, Baack B, Smith BD, et al. Eradication of hepatitis $\mathrm{C}$ virus infection and the development of hepatocellular carcinoma: a meta-analysis of observational studies. Ann Intern Med 2013;158:329-37.

4. Ioannou GN, Green PK, Berry K. HCV eradication induced by direct-acting antiviral agents reduces the risk of hepatocellular carcinoma. J Hepatol 2017. [Epub ahead of print].

5. Calvaruso V, Cabibbo G, Cacciola I, et al. Rete Sicilia Selezione Terapia-HCV (RESIST-HCV). Incidence of hepatocellular carcinoma in patients with $\mathrm{HCV}$-associated cirrhosis treated with direct-acting antiviral agents. Gastroenterology 2018;155:411-21.e4.

6. Ioannou GN, Green PK, Beste LA, et al. Development of models estimating the risk of hepatocellular carcinoma after antiviral treatment for hepatitis C. J Hepatol 2018;69:1088-98.

7. Ioannou GN, Beste LA, Green PK, et al. Increased risk for hepatocellular carcinoma persists up to 10 years after HCV eradication in patients with baseline cirrhosis or high FIB4 scores. Gastroenterology 2019;157:1264-78.

Cite this article as: Maida M, Macaluso FS. Incidence of hepatocellular carcinoma after HCV eradication: assessing the risk. HepatoBiliary Surg Nutr 2020;9(2):255-256. doi: 10.21037/ hbsn.2019.10.17 